\title{
Experience of, and Perception on Gender Based Violence (GBV) by Pregnant Women in South Eastern Nigeria
}

\author{
Joseph Ifeanyi Brian-D. Adinma1 ${ }^{*}$, Victor Nwabunwanne Oguaka1, Joseph Odiri Ugbaja1, \\ Osita Samuel Umeononihu1, Nneoma Dolores Adinma-Obiajulu1, Odira Linda Okeke ${ }^{2}$ \\ ${ }^{1}$ Department of Obstetrics and Gynaecology, Nnamdi Azikiwe University and Teaching Hospital, Nnewi, Nigeria \\ ${ }^{2}$ Department of Nursing Sciences, Nnamdi Azikiwe University and Teaching Hospital, Nnewi, Nigeria \\ Email: ^brianadinma@yahoo.com
}

How to cite this paper: Adinma, J.I.B., Oguaka, V.N., Ugbaja, J.O., Umeononihu, O.S., Adinma-Obiajulu, N.D. and Okeke, O.L. (2019) Experience of, and Perception on Gender Based Violence (GBV) by Pregnant Women in South Eastern Nigeria. Advances in Reproductive Sciences, 7, 113-124. https://doi.org/10.4236/arsci.2019.74013

Received: August 29, 2019

Accepted: November 22, 2019

Published: November 25, 2019

Copyright ( $\odot 2019$ by author(s) and Scientific Research Publishing Inc. This work is licensed under the Creative Commons Attribution International License (CC BY 4.0).

http://creativecommons.org/licenses/by/4.0/

\section{Open Access}

\begin{abstract}
Background: Gender-based violence (GBV) is a common women's sexual and reproductive right violation. Pregnancy could be associated with an increased risk of GBV. Objective: To determine the experience of, and perception on GBV by pregnant Nigerian women. Methodology: A questionnaire-based cross-sectional study involving 250 pregnant women from six selected health facilities in Anambra, Southeastern Nigeria was conducted to elicit their experience of, and perceptions on gender based violence. Data analysis employed statistical package for social sciences (SPSS) version 22.0. Statistical comparison of variables employed Chi-square test, with significance levels comprising of $\mathrm{p}<0.05$ at $95 \%$ confidence interval. Results: Only 80 (32.0\%) of the respondents were aware of GBV while $17(6.8 \%)$ and $20(8.0 \%)$ had experienced it in the index and previous pregnancies respectively. Physical violence was the most commonly experienced 18 (58.1\%), while marital quarrel and drunkenness were the most commonly perceived causes, 21 (26.3\%) apiece. Up to $33.7 \%$ of the respondents would report GBV to the law enforcement agencies; $22.5 \%$ would seek medical attention and only $2.5 \%$ would do nothing. The most common source of information on GBV was public lecture (32.5\%) followed by media (26.3\%). As high as $49(61.3 \%)$ of the respondents that are aware of GBV $(\mathrm{N}=80)$, thought that GBV could be prevented while up to 53 $(66.3 \%)$ were aware of the strategies for its prevention. Conclusion: Awareness of GBV in this study is low (32.0\%) while experience is even lower at $6.8 \%$, and $8.0 \%$ for the index and previous pregnancies respectively. Information on prevention strategies for GBV is also low. The need to develop comprehensive reproductive health $(\mathrm{RH})$ policy that incorporates GBV and its management, to be taught in educational institutions is highlighted. The im-
\end{abstract}


portance of public health lectures and the employment of various media platforms as reproductive right enlightenment modalities, towards creating awareness on the prevention and combat of GBV are also highlighted.

\section{Keywords}

Experience, Perception, Gender Based Violence, Pregnant Women, Southeastern Nigeria

\section{Introduction}

Gender-based violence (GBV) and violence against women (VAW) are terms often used interchangeably, as most violence against women is gender-based, and most GBV is inflicted by men on women and girls [1]. According to the international human rights law, violence against women constitutes all acts of gender-based violence that result in, or are likely to result in, physical, sexual, psychological or economic harm or suffering to women, including threats of such acts, coercion or arbitrary deprivation of liberty, whether occurring in public or in private life [2]. Gender-based violence (GBV) is violence that is directed against a woman because she is a woman or that affects women disproportionately [3]. GBV is the most prevalent human rights violation worldwide and at least one in every three women has been beaten, coerced into sex, or otherwise abused in her lifetime-most often by someone she knows, including her family member, an employer or a co-worker [4]. GBV is sub-divided into physical and non-physical forms of violence.

The health sector is an entry point for identifying GBV, and a visit to a health professional is usually the first, and sometimes only step for victims to access support and care. It becomes pertinent to improve on the capacity of health care professionals to identify and support victims of violence as this will in turn lead to prevention of and management of GBV [1]. The role of the healthcare professional is stratified into identification of GBV, undertaking a medical examination and providing medical care, documenting GBV, risk assessment and safety planning as well as referrals to other service providers [1].

GBV includes harmful acts, ranging from physical, sexual, psychological, economic violence (deprivation and neglect), harmful traditional practices and other violations. It is important for health care providers to bear in mind the numerous facets of GBV. Physical and sexual violence resulting in bodily injuries might be easier to detect but psychological and economic violence may be difficult to identify even though they also have significant negative consequences on women's health [1].

GBV against women in Nigeria occurs in many areas especially domestic and includes rape, battery by their husbands, verbal abuse, incest, female genital mutilation, forced marriage, child marriage, denial of right to choose spouse, denial of the right to own a property, refusal to permit women to work or to control 
their own income, refusal to allow the girl child to go to school, refusal of affection or sexual satisfaction, trafficking with the intention of using them as commercial sex workers and widowhood rites [5].

The WHO's world report on violence and health (first comprehensive review of the problem of violence on a global scale) shows that about one third of all the women in Nigeria had at one time or the other been a victim of violence in its diverse form [6]. In addition, it has been noted that the prevalence of domestic violence, female genital mutilations and forced prostitution are still high in $\mathrm{Ni}$ geria [7]. These are fuelled by socio-cultural beliefs that are inimical to well-being of the female gender [6]. Other factors that influence GBV include alcohol and tobacco usage by partners, married status, while older age appears to be protective against GBV [8]. Factors like educational level of the victim or the spouse as well as occupation do not influence the occurrence of GBV [8].

Violence has been noted to increase during pregnancy. Worldwide, one woman in every four is physically or sexually abused during pregnancy, usually by her partner. Violence during pregnancy varies from 3 percent to 11 percent among adult women and up to 38 percent among adolescent mothers [9]. Violence has serious consequences on pregnancy outcomes like increased risk of miscarriages, preterm labour, fetal distress, low birth weight infants and intrauterine fetal death. In Western India, $15.7 \%$ of pregnancy-related deaths in the community series and $12.9 \%$ in the hospital series were associated with domestic violence [10].

In Nigeria, pregnant women are highly prone to domestic violence [11]. This comes especially from their spouses and in-laws [12]. The commonest forms of violence experienced by the pregnant women according to a study carried out in the northern part of the country are physical assault followed by sexual abuse [12]. Another study in the country's capital city however, showed that a third of pregnant women had experienced one form of violence or another during pregnancy and that psychological abuse was the leading form of violence followed by physical and then sexual abuse [13]. Up to $20 \%$ of those who were physically abused required medical treatment, with the most frequent medical complication being premature labour [13]. The trend is the same across all the states and ethnicities in Nigeria [11]. This study has been undertaken among pregnant antenatal clinic attendees from southeastern Nigeria to elicit their experience of, and perceptions on gender-based violence-knowledge of category of GBV perpetrators, response following GBV, and awareness of any reproductive Health enlightenment program on GBV. Findings from this study will be useful in the development of policies on the prevention and management of GBV in pregnancy.

\section{Subjects and Method}

This is an interviewer-administered questionnaire-based, cross-sectional study involving 250 pregnant women attending antenatal clinic in four categories of selected health facilities in Anambra state of southeasten Nigeria from December 2017 to April 2018. The facilities include Nnamdi Azikiwe University Teaching Hospital, Nnewi, a tertiary health facility; Holy Rosary Specialist Hospital, Water 
side Onitsha, voluntary agency (mission hospital); Chidera Hospital, Nnewi, a private hospital; and Primary Health Centre, Nnobi all in Anambra state of Southeastern Nigeria.

Ethical clearance for the study was obtained from the ethical committee of the Nnamdi Azikiwe University Teaching Hospital.

Only antenatalclinic attendees who gave their consent were drawn into the study by simple random sampling. Verbal consent was obtained from the participants after due explanation of the objective of the study. The questionnaires were administered by trained interviewers, consisting of clinical medical and nursing students, under the supervision of a consultant obstetrician and gynaecologist. The information elicited from the respondents include their biosocial characteristics-age, parity, gestational age, their awareness and experience of GBV in the current or past pregnancies as well as causes and measures they think could be taken to curtail GBV. Others include knowledge of the categories of GBV perpetrators, response following GBV, and awareness of any reproductive Health enlightenment program on GBV.Completed questionnaire were analyzed using SPSS Version 22.0 and data displayed in tables.

\section{Results}

Table 1 shows the distribution by the bio-social characteristics of the pregnant women. The predominant age range of the participants was 25 - 29 years -78 (31.2\%), while the 15 - 19 years range constituted the least-15 (6.0\%). Most of the study participants were multiparous 158 (63.2\%); 68 (27.2\%) were nulliparous; while only $24(9.6 \%)$ were grand multiparous women. The highest number of participant were in the gestational age range of 14 - 26 weeks, 105 (42.0\%); followed by 27 - 40 weeks gestational age range, 103 (41.2\%).

Up to $90(36.0 \%)$ of the participants had tertiary educational qualification; 142 (56.8\%) had secondary; $16(6.4 \%)$ had primary; while only $2(0.8 \%)$ had no formal educational qualification.

As high as $110(44.0 \%)$ of the participants were traders; $61(24.4 \%)$ were civil servant; 43 (17.2\%) were students; while 31 (12.4\%) were house wives.

Table 2 shows the Distribution by awareness of and perceived causes of GBV by the participants. Only 80 (32.0\%) were aware of GBV; $170(68.0 \%)$ were not. Quarrels and drunkenness 21 (26.3\%) each, were believed to be the most common cause of GBV, while 10 (12.5\%) perceived rejection of sexual advances, as a cause. Cultural practices were believed to be a cause by 20 (25\%); while lack of co-operation with health workers was perceived to be the cause of GBV in 2 (2.5\%).

Table 3 shows the distribution by experience of GBV in the index and past pregnancy, together with the categories of GBV experienced. Seventeen participants $(6.8 \%)$ had experienced GBV in the index pregnancy while $20(8.0 \%)$ had experienced it in previous pregnancies. Physical violence as typified by battery was the commonest GBV experienced and occurred in $58.1 \%$ of cases, followed by psychological violence $(35.4 \%)$ and economic violence $(6.5 \%)$. None of the participants had been sexually violated in pregnancy. 
Table 1. Distribution by the biosocial characteristics of the pregnant women.

\begin{tabular}{|c|c|c|}
\hline Age (years) & Frequency & Percentage \\
\hline $15-19$ & 15 & 6.0 \\
\hline $20-24$ & 65 & 26.0 \\
\hline $25-29$ & 78 & 31.2 \\
\hline $30-34$ & 58 & 23.2 \\
\hline $35-39$ & 18 & 7.2 \\
\hline$>39$ & 16 & 6.4 \\
\hline \multicolumn{3}{|l|}{ Parity } \\
\hline 0 & 68 & 27.2 \\
\hline $1-4$ & 158 & 63.2 \\
\hline$>4$ & 24 & 9.6 \\
\hline \multicolumn{3}{|l|}{ Gestational Age (Weeks) } \\
\hline $0-13$ & 29 & 11.6 \\
\hline $14-26$ & 105 & 42.0 \\
\hline $27-40$ & 103 & 41.2 \\
\hline$>40$ & 13 & 5.2 \\
\hline \multicolumn{3}{|l|}{ Educational Level } \\
\hline No Formal Education & 2 & 0.8 \\
\hline Primary & 16 & 6.4 \\
\hline Secondary & 142 & 56.8 \\
\hline Tertiary & 90 & 36.0 \\
\hline \multicolumn{3}{|l|}{ Occupation } \\
\hline House Wife & 31 & 12.4 \\
\hline Trading & 110 & 44.0 \\
\hline Student & 43 & 17.2 \\
\hline Civil Servant & 61 & 24.4 \\
\hline Others & 5 & 2.0 \\
\hline
\end{tabular}

Table 2. Distribution by awareness of and perceived causes of GBV by the participants.

\begin{tabular}{ccc}
\hline Awareness of GBV & Frequency & Percentage \\
\hline Yes & 80 & 32.0 \\
No & 170 & 68.0 \\
Causes of GBV $(\mathbf{N}=\mathbf{8 0})$ & & \\
Quarrels & 21 & 26.3 \\
Drunkenness & 21 & 26.3 \\
Refusal to consent to sexual advances & 10 & 12.5 \\
Perceived lack of co-operation with health workers & 2 & 2.5 \\
Cultural practices & 20 & 25 \\
Others & 1 & 1.5 \\
\hline
\end{tabular}


Table 3. Distribution by experience of GBV in the index and past pregnancy, together with the categories of GBV experienced.

\begin{tabular}{ccc}
\hline Experience/category of GBV & Frequency & Percentage \\
\hline Experience in the index pregnancy & 17 & 6.8 \\
Yes & 233 & 93.2 \\
No & & \\
Experience in previous pregnancies & 20 & 8.0 \\
Yes & 230 & 92.0 \\
No & 31 & 12.4 \\
Overall experience & & \\
Category of GBV experienced & 18 & 58.1 \\
Physical (e.g. battery) & 11 & 35.4 \\
Psychological (e.g. verbal abuse) & 0 & 0 \\
Sexual (e.g. rape) & 2 & 6.5 \\
Economic (deprivation/neglect) & 31 & 100.0 \\
Total & & \\
\hline
\end{tabular}

Table 4 shows the distribution by categories of GBV experienced for perpetrators. The spouse consistently remain the highest perpetrator of GBV for the various categories-7 (38.9\%) for physical violence; 4 (36.3\%) for psychological violence; and $2(100 \%)$ for economic violence. For physical violence, in-laws 5 (27.8\%) ranked second followed by employer 4 (22.2\%), while for psychological violence however, relations and friend ranked second, 3 (27.3\%) each followed by in-laws 1 (9.1\%). None of the participants experienced sexual violence or traditional harmful practices.

Figure 1 shows the distribution by the participants' responses to GBV. Up to $27(33.7 \%)$ of the respondents will report an incidence of GBV to the law enforcement agency; 18 (22.5\%) will seek medical attention; while 15 (18.8\%) will report to the kindred. Nine (11.3\%) will seek spiritual counsel; $5(6.3 \%)$ will respond by retaliation; while only 2 (2.5\%) of the participants will do nothing.

Table 5 shows the distribution by respondent's awareness of reproductive health enlightenment, and sources of information, on GBV.

As high as $57(71.3 \%)$ of the respondents were aware of reproductive health enlightenment programs on GBV. The commonest source of information by the respondents was public lecture 26 (32.5\%); followed by the media 21 (26.3\%).

The distribution by the awareness of prevention of, and prevention strategies of, GBV as shown in Table 6 indicates that up to 49 (61.3\%) of the respondents believed GBV can be prevented; Fifty-three (66.3\%) were aware of the prevention strategies. The most common preventive strategies of GBV known by the respondent was violence against person prohibition act 13 (24.5\%), followed by legislative bills $12(22.6 \%)$, while reporting to the health facility constituted the least 8 (15.1\%). 
Table 4. Distribution by categories of GBV experienced for perpetrators.

\begin{tabular}{cccccc}
\hline & \multicolumn{5}{c}{ Perpetrators } \\
\cline { 2 - 6 } Categories of GBV & $\begin{array}{c}\text { Spouse } \\
\mathrm{N}(\%)\end{array}$ & $\begin{array}{c}\text { Relations } \\
\mathrm{N}(\%)\end{array}$ & $\begin{array}{c}\text { Friends } \\
\mathrm{N}(\%)\end{array}$ & $\begin{array}{c}\text { In-laws } \\
\mathrm{N}(\%)\end{array}$ & $\begin{array}{c}\text { Employer } \\
\mathrm{N}(\%)\end{array}$ \\
\hline Physical (Battery) N = 18 & $7(38.9)$ & $1(5.5)$ & $1(5.5)$ & $5(27.8)$ & $4(22.2)$ \\
Psychological (Verbal Abuse) N = 11 & $4(36.3)$ & $3(27.3)$ & $3(27.3)$ & $1(9.1)$ & $0(0)$ \\
Economic (Deprivation/Neglect) N = & $2(100)$ & $0(0)$ & $0(0)$ & $0(0)$ & $0(0)$ \\
Sexual (Rape) & $0(0)$ & $0(0)$ & $0(0)$ & $0(0)$ & $0(0)$ \\
Traditional Harmful Practices & $0(0)$ & $0(0)$ & $0(0)$ & $0(0)$ & $0(0)$ \\
\hline
\end{tabular}

Table 5. Distribution by respondent's awareness of reproductive health enlightenment, and sources of information, on GBV.

\begin{tabular}{ccc}
\hline $\begin{array}{c}\text { Awareness of Reproductive } \\
\text { Health Enlightenment on GBV }(\mathbf{N}=\mathbf{8 0})\end{array}$ & Frequency & Percentage \\
\hline Yes & 57 & 71.3 \\
No & 23 & 28.8 \\
TOTAL & 80 & 100.0 \\
Source Of Information $(\mathbf{N}=\mathbf{5 7})$ & & \\
Public Lectures & 26 & 32.5 \\
Peer Group & 10 & 12.5 \\
Media & 21 & 26.3 \\
\hline
\end{tabular}

Table 6. The distribution by the awareness of prevention of, and prevention strategies of, GBV.

\begin{tabular}{ccc}
\hline Characteristics & Number & Percentage \\
\hline Can GBV Be Prevented? $(\mathbf{N}=\mathbf{8 0})$ & 49 & 61.3 \\
Yes & 28 & 35 \\
No & 3 & 3.8 \\
Don't Know & & \\
Awareness of the Strategies to Prevent GBV (N = 80) & 53 & 66.3 \\
Yes & 25 & 31.3 \\
No & 2 & 2.5 \\
Don't know & & 16.9 \\
Preventive Strategies Known (N = 53) \\
Report to law enforcement agencies \\
Report to the health facility \\
Report to NGOs \\
Legislative bill \\
Violence against persons prohibition act & 9 & 15.1 \\
& 11 & 20.8 \\
\hline
\end{tabular}




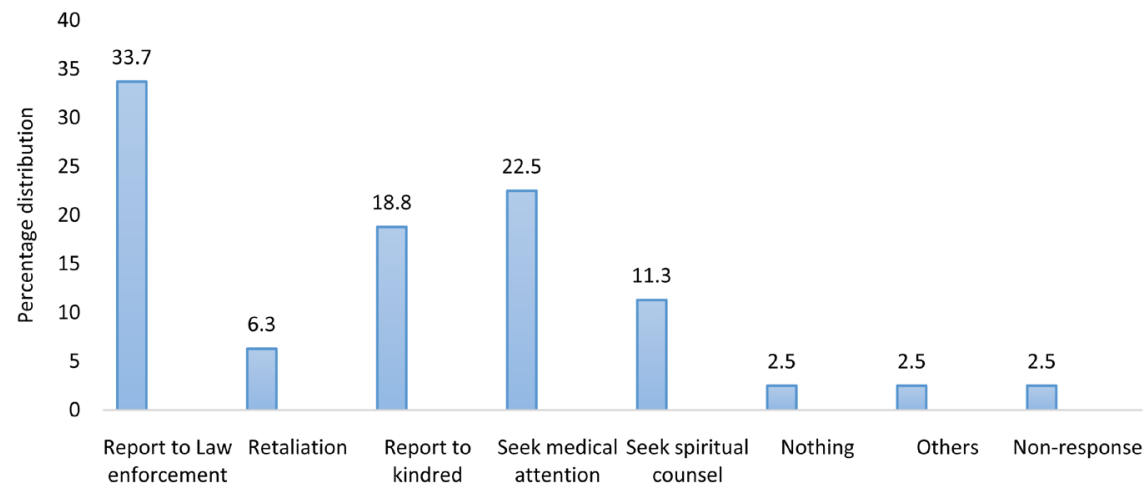

Figure 1. Distribution by participants' responses to GBV.

\section{Discussion}

Gender-based violence (GBV) is a global public health problem occurring within the home (domestic) or in the wider community and it affects both genders disproportionately. The level of awareness of GBV of $32 \%$ among the participants in this study was dismally low. This is in sharp contrast to the findings from the study conducted in Nigeria's federal capital territory where the level of awareness was $92.9 \%$ [13]. The difference may be because the later was carried out in a city while the former was carried out in semi-urban and rural settings.

Eight percent of the participants had experienced GBV in their previous pregnancies while $6.8 \%$ had experienced it in the index pregnancy. These figures agree with worldwide prevalence rate of $3 \%-11 \%$ [9] but appear to be at variance with the figures elsewhere in Nigeria with report of GBV prevalence rate of 1 in 3 pregnant women [13]. Worthy of note also is the fact that in a previous study carried out in the same area as the present study, as high as $40 \%$ prevalence rate of GBV was reported among women of child-bearing age within a preceding 12 months period [14]. This may imply that considerable restraint is exercised in meting out gender based violence to pregnant women in this study area. In general however, low prevalence rate of GBV in pregnancy observed in various studies may not be unrelated to under-reporting of the actual occurrences due to societal stigmatization of victims or by institutional failure to effectively assess, report and protect the victims at the community level [15]. Furthermore, even when cases are reported to the law-enforcement agencies like the police, they ultimately tend to be settled informally since most cases are viewed as private matters, with the victim or her family withdrawing the case due mainly to fear of stigmatization.

The most commonly perceived cause of GBV amongst the respondents in this study was marital quarrel and drunkenness, $26.3 \%$ apiece; followed by refusal of the woman to consent to sexual advances $12.5 \%$. Theses perhaps may explain the reason for the spouse being the most common perpetrator of GBV, observed in this study.

The commonest form of GBV experienced by the victims in this study was physical violation (58.1\%) followed by psychological violation (35.4\%) and eco- 
nomic violation $(6.5 \%)$. This trend is similar to that reported in a northern $\mathrm{Ni}$ gerian study where physical violation was also commonly observed followed by psychological violation [12]. The trend however is in contradistinction to the observation from the study carried out in Nigerian federal capital territory where psychological violation (66.4\%) was the commonest form of GBV followed by physical (23.4\%), and sexual violation (10.2\%) [13]. None of the respondents in this study was sexually violated.

The spouse was the commonest perpetrator of GBV, occupying the first position in all the categories and accounting for $38.9 \%, 36.3 \%$ and $100.0 \%$ of physical, psychological and economic violations respectively. A similar observation has been made in a previous study conducted in Nigeria where the husband/spouse had been reported to be responsible for as high as $74.2 \%$ of GBV [13]. This prime place occupied by the spouse as the perpetrator of GBV may perhaps call for the establishment of paternal education classes that will impact appropriate information and counselling on the dangers of gender based violence and other similar vices during pregnancy, to this foremost important segment of maternity care. The response of the participants in this study as to what they would do when confronted with GBV presents a mix picture ranging from reporting to the law enforcement agency (33.7\%), through seeking medical attention (22.5\%), reporting to the kindred (18.8\%), seeking spiritual counsel (11.3\%), retaliating (6.3\%) and to doing nothing (2.5\%). It is pertinent to note that up to $22.9 \%$ of respondent would report a GBV encounter to medical center to seek medical attention. This undoubtedly buttresses the importance of the health sector as the entry point for identification, management (and referrals to other service providers), as well as support for the victims including prevention of recurrence of GBV. The law-enforcement agency to which majority of the respondents would report, also plays a pivotal role in GBV management, as it may need to work closely with the healthcare providers during its investigations. In addition it is important in not just prosecuting the culprits or the perpetrator but also in the protection of the victims from intimidation and further assault. The importance of the clergy in GBV is evident in this study since up to $12.2 \%$ of the respondent would seek spiritual counsel. This observation also highlights the important place occupied by spirituality and religion as an instrument of solace by people of this area when confronted with challenges of various forms and dimensions.

Among the 80 respondents in this study that are aware of GBV up to 27 (33.75\%) are unaware of any preventive strategies of GBV, leaving only 53 (66.3\%) with perceived knowledge of the preventive strategies for GBV. These group represent only a mere $21.2 \%$ of the overall 250 pregnant women involved in this study thereby highlighting the magnitude of the ignorance of GBV among the women of this study area. Of the preventive strategies, the respondents claimed knowledge of, violence against the persons prohibition (VAPP) act (24.5\%) and Legislation (22.6\%) ranked highest-probably indicating the efforts of some reproductive health-non-governmental organisations has played on the dissemination of and public enlightenment on the VAPP act passed by the federal house 
of assembly and signed into law in 2014. Incidentally the VAPP act is presently applicable only to the federal capital territory and is yet to be domesticated in the other 36 states of the Nigerian federation.

In this study, up to $23(28.8 \%)$ of the respondents who are aware of GBV have no knowledge of any reproductive health enlightenment program. Of the 57 (71.3\%) of the participants that have knowledge, public lecture $(32.5 \%)$ constitute the highest source of information followed by the media $(26.3 \%)$, with peer group (12.5\%) trailing. This development is interesting considering the part peer group (an unreliable source of RH information) has played as a source of information in reproductive health studies conducted in previous decades [16] [17]. Surprisingly, the media constituted the source of information in only $26.3 \%$ of the respondents in this study. Nowadays, the social media and the internet play an important role as a source of reproductive health information, and effort should be made towards latching GBV enlightenment program into this important and friendly information platform.

\section{Conclusions}

The awareness of GBV in this study is poor and the experience amongst the respondents is relatively low. Low prevalence rate may undoubtedly be related to low levels of awareness amongst the participants in the study. Irrespective of the category of gender based violence-physical, psychological, economic and sexual, the spouse plays a leading role as the perpetrator of GBV. Among the respondents who are aware of GBV, intended action to be taken following a GBV encounter includes, reporting to the law enforcement agency, seeking medical attention, reporting to kindred and seeking spiritual counselling, while a few respondents would do nothing. There is overall poor knowledge of the preventive strategies for gender-based violence. The poor awareness of GBV in this study may signify the gap in reproductive health information among the pregnant women in the study area. It may also imply that majority of the respondents had no reproductive health information prior to their pregnancy. There is a need to develop a comprehensive reproductive health policy that incorporates GBV and its management.

Reproductive health program should be well articulated and GBV information entrenched in the program schedule. Gender-based violence information should be part of routine antenatal care health education to enable pregnant mothers to recognize and act on such violations. Spouses should on occasions during the antenatal care visits of their wives, be invited and be similarly informed on GBV and its negative consequences on their spouse and pregnancy. Pregnant mothers should be encouraged to speak up and report any gender based violations while appropriate actions should be seen to be taken following GBV. Reproductive health based non-governmental organizations should play a leading role in the dissemination of information in respect of GBV during, and out of pregnancy-making effective use of several media platforms. Gender based violence as 
an important aspect of women's sexual and reproductive rights infringement should be incorporated into the curriculum of medical education for nurses and medical students, and even at other levels of education-primary and secondary levels, under family life education. Creating awareness on gender-based violence - its causes and management will undoubtedly lead to its reduction and ultimately the promotion of women's sexual and reproductive rights.

\section{Limitations to the Study}

1) The research was hospital-based and as such does not capture the entire population of the study area;

2) The study was an interviewer-administered questionnaire-based study owing to the educational level of the participants;

3) The research lacks funding from any source and as such could not cover other geographical locations in the country of study.

\section{Conflicts of Interest}

The authors declare no conflicts of interest regarding the publication of this paper.

\section{References}

[1] UNFPA and WAVE (2014) Strengthening Health System Responses to Gender-Based Violence in Eastern Europe and Central Asia-A Resource Package. http://www.health-genderviolence.org/sites/default/files/download/WAVE-UNFPA \%20English.pdf

[2] The United Nations General Assembly (1993) Declaration on the Elimination of Violence against Women (DEVAW).

[3] Committee on the Elimination of Discrimination against Women (1992) General Recommendation No. 19, 1992-Violence against Women. (CEDAW GR 19).

[4] Minnesota Advocates for Human Rights (2003) What Is Gender-Based Violence? http://hrlibrary.umn.edu/svaw/advocacy/modelsessions/what_is_GBV.PDF

[5] Uwameiye, B.E. and Iserameiya, F.E. (2013) Gender Based Violence against Women and Its Implication on the Girl Child Education in Nigeria. International Journal of Academic Research in Progressive Education and Development, 2, 219-226.

[6] WHO (2002) World Report on Violence and Health. http://apps.who.int/iris/bitstream/handle/10665/42495/9241545615_eng.pdf;jsessio nid=38F62BC0C568ED3867B719435C0AEE8B? sequence $=1$

[7] Jekayinfa, A.A. (2018) Types Causes and Effects of Gender Based Violence: Challenges for Social Studies in Nigeria. https://www.coursehero.com/file/15257744/gender-based-violence/

[8] Oladepo, O., Yusuf, O.B. and Arulogun, O.S. (2011) Factors Influencing Gender Based Violence among Men and Women in Selected States in Nigeria. African Journal of Reproductive Health, 15, 78-86. https://doi.org/10.4314/afrrev.v4i4.69233

[9] Lori, H., Ellsberg, M. and Gottemoeller, M. (2014) Ending Violence against Women. Population Reports, 1999, Series L. No. 11. The Free Library.

https://www.thefreelibrary.com/Heise\%2c+Lori\%3b+Ellsberg\%2c+Mary\%3b+Gotte moeller\%2c+Megan.+1999.+\%22Ending...-a095448520 
[10] Ganatra, B.R., Coyaji, K.J. and Rao, V.N. (1996) Community Cum Hospital Based Case-Control Study on Maternal Mortality: A Final Report. KEM Hospital Research Centre, Pune, India, 62.

[11] Wikipedia Contributors (2017) Domestic Violence in Nigeria. Wikipedia, the Free Encyclopaedia.

https://www.thefreelibrary.com/Heise $\% 2 \mathrm{C}+$ Lori\%3B+Ellsberg\%2C+Mary\%3B+Got temoeller\%2C+Megan.+1999.+\%22Ending...-a095448520

[12] Ameh, N. and Abdul, M.A. (2004) Prevalence of Domestic Violence amongst Pregnant Women in Zaira, Nigeria. Annals of African Medicine, 3, 4-6.

[13] Efetie, E.R. and Salami, H.A. (2007) Domestic Violence on Pregnant Women in Abuja, Nigeria. Journal of Obstetrics and Gynaecology, 27, 379-382.

https://doi.org/10.1080/01443610701327552

[14] Ilika, A.L., Okonkwo, P.I. and Adogu, P. (2002) Intimate Partner Violence among Women of Childbearing Age in a Primary Health Care Centre in Nigeria. African Journal of Reproductive Health, 6, 53-58. https://doi.org/10.2307/3583257

https://www.researchgate.net/publication/43561970_Intimate_Partner_Violence_amo ng_Women_of_Childbearing_Age_in_a_Primary_Health_Care_Centre_in_Nigeria

[15] Para-Mallam, F.J. (2018) Gender-Based Violence in Nigeria: A Comparative Review of Violence Affecting Women and Girls in Selected States.

https://www.researchgate.net/publication/320462653_Gender-Based_Violence_in_Ni geria_A_Comparative_Review_of_Violence_Affecting_Women_and_Girls_in_Selec ted_States

[16] Adinma, J.I.B. and Nwosu, B.O. (1995) Family Planning Knowledge and Practice among Nigerian Women Attending an Antenatal Clinic. Advances in Contraception, 11, 335-334. https://doi.org/10.1007/BF01983293

[17] Adinma, J.I.B. and Okeke, A.O. (1995) Contraception: Awareness and Practice among Nigeria Tertiary School Girls. West African Journal of Medicine, 14, 34-37. 